\title{
A Randomised, Prospective Comparison of ND:YAG Laer Iridotomy and Operative Peripheral Iridectomy in Fellow Eyes
}

\author{
B. W. FLECK, B. DHILLON, V. KHANNA, E. FAIRLEY, C. MCGLYNN \\ Edinburgh
}

\begin{abstract}
Summary
A prospective, randomised comparison of Nd:YAG laser iridotomy and operative peripheral iridectomy in the fellow eye of 52 patients presenting with acute angle closure glaucoma has been undertaken. Nd:YAG laser iridotomy resulted in a significantly higher incidence of iris bleeding at the time of treatment $(p<0.05)$, higher intraocular pressure one hour $(\mathbf{p}<0.02)$ and three hours $(\mathbf{p}<0.02)$ following treatment, and a higher incidence of focal corneal oedema 24 hours following treatment $(\mathbf{p}<0.001)$. One laser treated patient developed acute angle closure glaucoma two weeks following treatment despite the presence of a small patent iridotomy.

After a mean follow-up period of $\mathbf{1 1 . 8}$ months there was no significant difference between the two groups in visual acuity, or intraocular pressure. It is concluded that Nd:YAG laser iridotomy is a satisfactory alternative to operative peripheral iridectomy in the prophylactic treatment of fellow eyes.
\end{abstract}

Argon $^{1}$ and $\mathrm{Nd}: \mathrm{YAG}^{2}$ laser iridotomy have already largely superseded operative peripheral iridectomy ${ }^{3}$ in the treatment of angle closure glaucoma. ${ }^{4}$ Laser surgery is more convenient and less costly than conventional surgery. ${ }^{5} \quad$ Rare but serious operative complications such as endophthalmitis, flat anterior chamber and malignant glaucoma, are completely eliminated. However laser surgery should not be regarded as non invasive. $^{6}$

Several studies have compared argon laser and Nd:YAG laser iridotomy. Nd:YAG laser iridotomy requires less laser energy, produces fewer short term complications, and has a much lower rate of delayed iridotomy closure than argon laser iridotomy. ${ }^{7-12} \mathrm{Nd}$ :YAG laser iridotomy hs not been compared with operative peripheral iridectomy in a prospective study. Peripheral iridectomy is a remarkably 'safe' operation, with few short or long term complications. ${ }^{13}$ We are currently performing a long term prospective randomised comparison of these treatments in a variety of forms of angle closure glaucoma, and our initial results in the treatment of the fellow eye following acute angle closure glaucoma are presented in this paper.

\section{Material and Method}

Ethical approval of the study was obtained from the Regional Surgical Specialties Ethical Committee. Consecutive patients with acute angle closure glaucoma in one eye were accepted into the trial if the referring opthalmologist believed the patient to be suitable for either Nd:YAG laser iridotomy or operative peripheral iridectomy in the fellow eye. If the fellow eye had an intraocular pressure greater than $21 \mathrm{mmHg}$ or a cup:disc ratio greater than 0.6 the patient was excluded from the study. Informed patient consent to 
inclusion in the trial was obtained before randomisation.

Initial examination included assessment of corrected visual acuity, intraocular pressure, Goldman gonioscopy, slit lamp examination of the lens, and fundal examination. Specular microscopy was performed using a KeelerKonan Pocklington specular microscope. Several central fields were photographed and stored for later analysis.

Forty-eight hours prior to surgical or laser treatment all systemic and topical introcular pressure lowering agents, other than G Pilocarpine $2 \%$, were discontinued. One drop of $\mathrm{G}$ Pilocarpine $2 \%$ was instilled one hour before treatment.

\section{Surgery}

Operative peripheral iridectomy was performed under general anaesthetic, or subconjunctival local anaesthetic. Retrobulbar local anaesthetic was not used, in order to avoid possible intraocular pressure changes induced by this procedure during the early postoperative period.

\section{Laser treatment}

A Zeiss 'Visulas' Nd:YAG laser and Zeiss anterior segment YAG contact lens were used. A treatment site was chosen in the superior iris, between 10 and 2 o'clock, approximately $2 / 3$ distance from the pupil margin to the base of the iris. An iris crypt was used, when present. A single $5-10 \mathrm{mj}$ pulse was delivered to the treatment site. If this pulse did not penetrate the iris, further single pulses were delivered to the same site until penetration was achieved. A gush of aqueous fluid from the posterior chamber could be seen at the moment of penetration. Patency was assessed by direct observation of the posterior chamber, or anterior lens capsule.

\section{Post treatment assessment}

Goldman applanation tonometry was performed one, two, three, six and 24 hours following treatment. A Perkins hand held applanation tonometer was used to measure the early post operative intraocular pressure in some surgical patients who had had a general anaesthetic. Systemic and topical intraocular pressure lowering agents were withheld unless the pressure rose above $40 \mathrm{~mm} \mathrm{Hg}$.

Twenty four hours after treatment the cornea was examined and focal endothelial damage scored as 0 (no change present), + (focal granularity), or ++ (focal full thickness corneal oedema). Iritis was judged to be present if there were more than five white cells per field using a $3 \mathrm{~mm}$ long slit beam.
The presence of dispersed pigment particles in the aqueous was not judged to be indicative of iritis. Intraocular pressure was measured, the iridotomy or iridectomy inspected for patency, and the lens examined. No topical treatment was given unless significant iritis was present, in which case G Betamethasone $0.1 \%$ four times daily for one week was prescribed. Mydriatics were not used.

\section{Follow up}

Patients were assessed one week, one month, six months, and 12 months following treatment. The pupil was dilated using G. Phenylephrine $10 \%$ one month following treatment in order to detect posterior synechiae, and to examine the lens and fundus. Six months following treatment specular microscopy, gonioscopy and pilocarpine/phenylephrine provocation testing were performed. Goldman gonioscopy was performed on all patients, followed by Zeiss 4 mirror indentation gonioscopy if any part of the angle appeared to be closed. Pilocarpine/phenylephrine provocation testing as described by Mapstone ${ }^{14}$ and modified by Harrad $^{15}$ was used. One drop of G Phenylephrine $10 \%$ and one drop of $\mathrm{G}$ Pilocarpine $2 \%$ were instilled. The intraocular pressure was measured one hour later. An intraocular pressure rise of more than $8 \mathrm{~mm} \mathrm{Hg}$ was regarded as a positive result. ${ }^{14}$

\section{Specular microscopy analysis}

Patients were coded by number, and endothelial cell counts were performed by an observer unaware of the coding system. Using standardised print magnification and a transparent grid, three representative fields of $0.05 \mathrm{~mm}^{2}$ were chosen for each patient, and the cells within these fields were counted. The mean value for the three areas was then calculated.

\section{Statistical analysis}

Where appropriate the unpaired Student $t$ test or the chi squared test were used to test the signifcance of differences between the two groups.

\section{Results}

Twenty six patients in each group have now completed at least six months of follow-up. Thirteen patients from the surgical group and sixteen patients from the laser treated group have completed one year of follow-up. The current mean follow-up time for the surgical group is $11.7 \pm 8.7$ months, and that of the laser treated group $16.1 \pm 11.0$ months ( $t$ test NS). Two patients in the laser treated group have died, in each case approximately nine 
Table I Patient Groups

\begin{tabular}{lccc}
\hline & Surgery & Laser & $P$ \\
\hline Number & 26 & 26 & \\
Male:Female & $9: 17$ & $7: 19$ & \\
Age (years) & $67.5 \pm 13.1$ & $68.3 \pm 12.6$ & NS \\
Age range & $41-88$ & $40-88$ & \\
Right:Left & $10: 6$ & $11: 15$ & \\
\hline
\end{tabular}

Figures are presented as mean \pm one standard deviation.

$\mathrm{P}=$ statistical $\mathrm{p}$ value, $\mathrm{NS}=$ Not statistically significant.

months following treatment. No patients have been lost to follow-up.

Details of initial assessment of the two groups are given in Tables I and II.

A patent laser iridotomy was obtained at the initial treatment session in 25 patients. Treatment sessions on three consecutive days were needed to obtain a patent iridotomy in one patient. A patent iridectomy was produced in all surgical patients. A mean of $3.1 \pm 2.6$ pulses (range $1-10$ ) with a mean total energy of $25.8 \pm 21.4 \mathrm{~mJ}$ (range 4.972.9) was used in laser treatment. One pulse was sufficient to create an adequate iridotomy in 11 patients, and less than $10 \mathrm{~mJ}$ total energy was used in 10 patients. Slight iris bleeding occurred at the time of treatment in 15 laser patients and seven surgical patients $\left(\mathrm{X}^{2}\right.$ test $\mathrm{p}<0.05)$. There were no other operative complications.

\section{Immediate post treatment assessment}

The mean intraocular pressure before treatment and one, two, three and six hours following treatment are shown in Fig. 1. Complete data was available in nine surgically treated patiens and 15 laser treated patients. The groups were significantly different at one hour and three hours using the unpaired student $t$ test, $p<0.02$. Two surgically treated patients $(8 \%)$ developed an intraocular pressure rise to between 20 and $25 \mathrm{~mm} \mathrm{Hg}$ within three hours of surgery. Seven laser treated patients $(27 \%)$ developed an intraocular pressure rise to greater than $20 \mathrm{~mm} \mathrm{Hg}$ within three hours of treatment, and in three of these patients the intraocular pressure rose to above $40 \mathrm{~mm} \mathrm{Hg}$.

Of the 15 laser treated patients with complete intraocular pressure data, the peak pressure occurred one hour following treatment in seven, at two hours in four, and at three hours in four. In all but two cases the intraocular pressure had returned to normal six hours following treatment.

The results of examination 24 hours following treatment are shown in Table III.

Focal corneal oedema was most marked 24 hours following laser treatment, and had fully resolved after one week in all cases. The total laser energy used to treat the 15 patients who subsequently developed focal corneal oedema was $30.95 \pm 21.6 \mathrm{~mJ}$, compared to $18.2 \pm 19.7 \mathrm{~mJ}$ for those who did not. This difference was not statistically significant. The total laser energy used to treat the six patients who subsequently developed iritis was $39.75 \pm 16.2 \mathrm{~mJ}$, compared to $20.7 \pm 18.2 \mathrm{~mJ}$ for those who did not. Again this difference was not statistically significant.

Six surgical patients were found to have minimal focal lens opacities at the iridectomy site due to mild operative trauma to the anterior lens capsule. These opacities were not progressive and did not lead to visual loss during the follow-up period. Two laser treated patients developed focal lens opacities underlying the treatment site. In one case a faint haze was present deep to the anterior capsule, with no subsequent progression or loss of vision. The second case developed polychromatic crystals in the anterior lens cortex underlying the treatment site, with sub-

Table II Initial Examination

\begin{tabular}{lccc}
\hline & Surgery & Laser & $P$ \\
\hline Visual acuity worse than 6/9 due to cataract & 3 & 4 & $\mathrm{NS}$ \\
Intraocular pressure, mm Hg & $15.0 \pm 3.6$ & $15.5 \pm 3.4$ & $\mathrm{NS}$ \\
Gonioscopy (Goldman) angle partly closed & 6 & 6 & $\mathrm{NS}$ \\
Iris colour Brown:Grey & $10: 16$ & $10: 16$ & $\mathrm{NS}$ \\
\hline
\end{tabular}

$P=$ statistical $p$ value, $N S=$ Not statistically significant. 


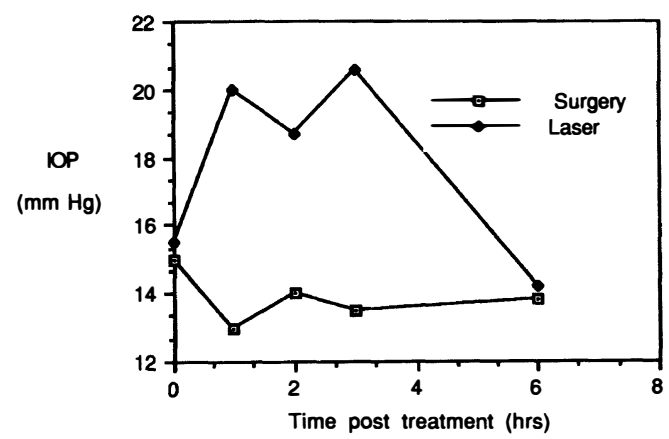

Fig. 1. Early post treatment intraocular pressure.

sequent development of nuclear cataract and loss of one line of visual acuity, from $6 / 9$ to $6 / 12$.

\section{One month follow-up}

One laser treated patient developed acute angle closure glaucoma three weeks following treatment. The patient had been using cyclopentolate $1 \%$ drops to the other eye, and may have inadvertently contaminated the affected eye. Following treatment with pilocarpine $2 \%$ the intraocular pressure returned to normal. The iridotomy was small $(50 \mu \times 50 \mu)$ but patent. Nd:YAG laser enlargement of the iridotomy was performed, resulting in no further symptoms. A subsequent pilocarpine/ phenylephrine provocation test was negative.

One patient was found to have developed iridotomy closure two weeks following treatment and further laser treatment to re-open the iridotomy was performed.

Posterior synechiae developed in three surgical patients, and three laser treated patients. Two of the surgical patients and one of the laser treated patients had had iritis at the 24 hours post treatment examination. The adhesions were of minimal extent in all cases, did not progress, and were not associated with subsequent cataract development or visual loss during the follow-up period of the study.

\section{Six month follow-up}

Table IV summarises the findings in the two groups of six months following treatment.

When compared with pre-treatment measurements visual acuity was unchanged, or changed by only one line in all surgical patients. However in the laser treated group visual acuity deteriorated by two or more lines in two patients. These patients had developed nuclear cataract-one in a previously clear lens, and one in a lens with pre-existing nuclear cataract.

The mean intraocular pressure was $14.5 \pm 2.7$ and $15.0 \pm 3.2 \mathrm{~mm} \mathrm{Hg}$ in the surgical and laser groups respectively. One laser treated patient had an intraocular pressure of $25 \mathrm{~mm} \mathrm{Hg}$. All other patients had an intraocular pressure of less than or equal to $21 \mathrm{~mm}$ $\mathrm{Hg}$, and no patient required topical medication.

All iridotomies and iridectomies were patent. Gonioscopy revealed an open angle in all surgical patients, with focal goniosynechiae adjacent to the iridectomy in two patients. Two laser treated patients had partly closed angles on Goldman gonioscopy, but the angles were open on indentation. One of these two patients had focal areas of goniosynechiae adjacent to the iridotomy site.

No patient developed more than a $10 \%$ change in the cup:disc ratio, and no patient developed pathological optic disc cupping.

Pilocarpine/phenylephrine provocation tests were performed on 14 surgical patients and 23 laser patients. All tests were negative.

Satisfactory pre-treatment and six months post treatment specular micrographs were obtained in seven surgical patients and nine laser treated patients (see Table V). The two groups did not significantly differ in mean endothelial cell count either before or six months following treatment. There was no significant percentage change in endothelial cell count following treatment in either group, and no difference between the two groups.

Table III Examination 24 hours following treatment.

\begin{tabular}{|c|c|c|c|}
\hline & Surgery & Laser & $P$ \\
\hline \multicolumn{4}{|l|}{ Focal corneal } \\
\hline $\begin{array}{l}\text { oedema } \\
\text { Grade + }\end{array}$ & 0 & $\begin{array}{l}15 \\
11\end{array}$ & $<0.001$ \\
\hline Grade: ++ & & 4 & \\
\hline \multicolumn{4}{|l|}{ Intraocular } \\
\hline $\begin{array}{l}\text { pressure, } \\
\mathrm{mm} \mathrm{Hg}\end{array}$ & $11.1 \pm 3.1$ & $12.2 \pm 4.0$ & NS \\
\hline Iritis & 11 & 6 & NS \\
\hline Patent & 26 & 26 & NS \\
\hline Focal lens opacities & 6 & 2 & NS \\
\hline
\end{tabular}


Table IV Examination 6 months following treatment

\begin{tabular}{lccc}
\hline & Surgery & Laser & $P$ \\
\hline Visual acuity loss of two or more lines & 0 & 2 & $\mathrm{NS}$ \\
Posteria synechiae & 3 & 3 & $\mathrm{NS}$ \\
Intraocular pressure, mm Hg & $14.5 \pm 2.7$ & $15.0 \pm 3.2$ & $\mathrm{NS}$ \\
Gonioscopy-angle partly closed & 0 & 2 & $\mathrm{NS}$ \\
Provocation test positive & 0 & 0 & $\mathrm{NS}$ \\
\hline
\end{tabular}

$\mathrm{P}=$ statistical $\mathrm{p}$ value, $\mathrm{NS}=$ Not statistically significant.

\section{Final follow-up}

At the final follow-up examination an additional two laser treated patients with initially clear lenses were found to have developed nuclear cataract sufficient to cause two or more lines of visual acuity loss. Visual acuity loss of more than one line did not occur in any surgical patient $\left(\chi^{2} \mathrm{NS}\right)$. The intraocular pressure at the final follow-up examination was $14.9 \pm 2.4 \mathrm{~mm} \mathrm{Hg}$ in the surgical group, and $14.3 \pm 2.4 \mathrm{~mm} \mathrm{Hg}$ in the laser treated group. No patient had an intraocular pressure greater than $21 \mathrm{~mm} \mathrm{Hg}$, but one laser treated patient was using topical $\beta$ blocker medication to maintain normal intraocular pressure.

\section{Discussion}

One laser treated patient developed acute angle closure glaucoma despite the presence of a small patent iridotomy. This case, and three other similar cases, have been discussed in another paper. ${ }^{16}$ Lowe found that conservative treatment of the fellow eye resulted in a $50 \%$ incidence of subsequent acute angle closure glaucoma. ${ }^{17}$ However, acute angle closure glaucoma following prophylactic surgical peripheral iridectomy is extremely rare. ${ }^{13,17,18}$ Small argon ${ }^{19,20}$ or Nd: $\mathrm{YAG}^{21-23}$ laser iridotomies may, however, fail to prevent acute angle closure glaucoma.

One case developed closure of a previously patent iridotomy, two weeks following treatment. This patient had not developed significant iritis following treatment. ND:YAG laser iriditomy closure is uncommon ${ }^{8,11,21-24}$ Late iridotomy closure, or partial closure, is much more common following argon laser iridotomy and has been reported to occur in approximately $20 \%$ of cases. ${ }^{10-12,15}$

\section{Short term complications}

Short term complications following Nd:YAG laser iridotomy include iris bleeding, intraocular pressure rise, focal corneal oedema, iritis and focal lens opacity.

Fifty-eight per cent of our laser treated patients developed iris bleeding at the time of treatment, a significantly higher incidence than that found during operative surgery. Other workers have reported an incidence of 20-60\% microhyphaema following Nd:YAG laser iridotomy. ${ }^{72,22,24}$ Macrohyphaema did not occur in our series, bleeding was transitory and did not appear to result in any adverse effect.

Our finding of transitory, but very marked, intraocular pressure elevation in some patients during the first three hours following $\mathrm{Nd}$ :YAG laser iridotomy confirms the findings of previous studies ${ }^{7-9,11,12,23,24}$ Timolol $^{25}$ and apraclonidine ${ }^{26}$ have been found to minimise the development of post-treatment intraocular pressure elevation, and it is now our practice to give acetazolamide $500 \mathrm{mg}$ orally one hour before performing Nd:YAG laser iridotomy.

Focal corneal endothelium changes overlying the treatment site occurred in $58 \%$ of

Table V Corneal endothelium cell density

\begin{tabular}{lccc}
\hline & Surgery & Laser & $P$ \\
\hline Pre-treatment cell density, $\mathrm{mm}^{-2}$ & $2470.3 \pm 522.7$ & $2531.7 \pm 649.1$ & NS \\
Post-treatment cell density, $\mathrm{mm}^{-2}$ & $2442.0 \pm 557.1$ & $2188.0 \pm 560.7$ & NS \\
Percentage change & $-3.6 \pm 3.95$ & $-7.2 \pm 10.6$ & NS \\
\hline
\end{tabular}

$\mathrm{P}=$ statistical $\mathrm{p}$ value, $\mathrm{NS}=$ Not statistically significant. 
our laser treated patients. Other workers have reported that $4-30 \%$ of eyes developed focal endothelial changes following Nd:YAG laser iridotomy. ${ }^{7,8,10,11,22,24}$ Punctate areas of endothelial loss overlying treatment sites have been attributed to damage caused by the dispersion of high velocity particulate debris. $^{27,28}$

Reduced endothelial cell density following argon laser iridotomy has been described by some workers, ${ }^{7}$ but others have found no change. ${ }^{29}$ We found no significant change in endothelial cell density following Nd:YAG laser iridotomy, confirming previous studies. ${ }^{7,30}$ No significant change in endothelial cell density following operative peripheral iridectomy was found in our study, again confirming the results of other workers. ${ }^{30,31}$

The incidence of iritis and posterior synechiae was similar following laser iridotomy and operative iridectomy. Focal lens opacities were found underlying the laser treatment site in two patients. Focal opacities induced by Nd:YAG laser photodisruption are rare,,$^{21,24,32}$ in contrast to a much higher incidence following argon laser iridotomy. ${ }^{1,7,10,11,12} \mathrm{We}$ found six cases of small focal lens opacities at the site of operative peripheral iridectomy. Focal opacities, whether caused by argon laser iridotomy, Nd:YAG laser iridotomy or operative peripheral iridectomy have previously been found to be non-progressive and do not lead to visual loss. However one of our laser treated patients lost one line of visual acuity due to nuclear cataract following the development of a focal opacity at the time of treatment.

\section{Long term glaucoma outcome}

There was no significant difference in the mean intraocular pressure of the two groups six months following treatment, or at the time of most recent follow-up. Optic disc appearance remained unchanged in all eyes, and gonioscopic appearances six months following treatment were similar in the two groups. Two laser treated eyes had areas of angle closure which could be opened on indentation. Wishart has reported progressive angle narrowing in four eyes following Nd:YAG laser iridotomy, with widening of the angle on performing a further laser iridotomy. ${ }^{21}$ It is possible that small iridotomies do not fully overcome iris bombé.

\section{Long term visual outcome}

While four laser treated patients lost two or more lines of visual acuity due to cataract development during the follow-up period, and no surgical patients lost vision, this difference was not statistically significant. Del Priore reported progression of cataract following Nd:YAG laser iridotomy in two of forty three patients. ${ }^{10}$ On long term follow-up approximately $10-15 \%$ of fellow eyes subjected to peripheral iridectomy develop cataract sufficient to reduce visual acuity by two or more lines. ${ }^{18,33}$ These figures compare with an incidence of $8 \%$ among fellow eyes treated conservatively. ${ }^{34}$

\section{Conclusion}

While the follow-up period of our study was only 11.8 months, our findings suggest that the short term complications of $\mathrm{Nd}$ :YAG laser iridotomy do not adversely affect the long term outcome. Short term complications may be minimised by appropriate iridotomy technique. Oral acetazolamide or a topical beta-blocker given prior to treatment will reduce the incidence of post treatment intraocular pressure elevation. ${ }^{25}$ The use of low energy laser pulses in conjunction with a Wise 103 dioptre contact lens should minimise endothelial trauma. ${ }^{9}$ The production of a large iridotomy will minimise the risk of subsequent acute angle closure glaucoma. ${ }^{16}$

Nd:YAG laser iridotomy and operative peripheral iridectomy appear to have a similar long term outcome. We are currently undertaking a five year prospective comparison of $\mathrm{Nd}$ :YAG laser iridotomy and operative peripheral iridectomy in 200 patients in order to test further this hypothesis. Bearing in mind the convenience of laser treatment, and the lack of possible anaesthetic complications, $\mathrm{Nd}$ :YAG laser iridotomy must remain the treatment of choice in angle closure glaucoma.

This study was supported by grants from the Edinburgh Royal Infirmary Eye Research Endowment Fund and the WH Ross Foundation. The preliminary findings of this study were presented at the Inaugural 
Congress of the College of Ophthalmologists, London, March 1989.

KEY wORDS: Angle Closure Glaucoma, Nd:YAG laser iridotomy, periheral iridectomy, specular microscopy.

\section{References}

${ }^{1}$ Abraham RK, Miller GL: Outpatient argon laser iridectomy for angle closure glaucoma: a two year study. Trans Am Acad Ophthalmol Otolaryng 1975;79:OP529-38.

${ }^{2}$ Frankhauser F, Roussel P, Steffen J, Van Der Zyphen E, Chrenkova A: Clinical studies on the efficiency of high power laser radiation upon some structures of the anterior segment of the eye. First experience of the treatment of some pathological conditions of the anterior segment of the human eye by means of a Q-switched laser system. Int Ophthalmol 1981;3:129-39.

${ }^{3}$ Chandler PA: Narrow Angle Glaucoma. Arch Ophthalmol 1952;47:695-716.

${ }^{4}$ Rivera AH, Brown RH, Anderson DR: Laser iridotomy vs surgical iridectomy - have the indications changed? Arch Ophthalmol 1985;103:1350-4.

${ }^{5}$ Rich W: The economics of Nd-YAG laser treatment. Dev Ophthalmol 1987;14:93-6.

${ }^{6}$ Spaeth GL: Laser treatment is invasive surgery. Ophthalmic Surg 1988;19:463-4.

${ }^{7}$ Robin AL and Pollack IP: A comparison of neodymium: YAG and argon laser iridotomies. $O p h$ thalmology 1984;91:1011-16.

${ }^{8}$ Schwartz LW, Moster MR, Spaeth GL, Wilson RP, Poryzees E: Neodymium: YAG laser iridotomies associated with closed or occludable angles. $\mathrm{Am} \mathrm{J}$ Ophthalmol 1986;102:41-4.

${ }^{9}$ Wise JB: Low-energy linear-incision neodymium: YAG laser iridotomy versus linear-incision argon laser iridotomy. A prospective clinical investigation. Ophthalmology 1987;94:1531-7.

${ }^{10}$ Del Priore LV, Robin AL, Pollack IP: Neodymium: YAG and argon laser iridotomy. Long-term follow-up in a prospective, randomized clinical trial. Ophthalmology 1988;95:1207-11.

${ }^{11}$ McAllister JA, Schwartz LW, Moster M, Spaeth GL: Laser peripheral iridectomy comparing Q-switched neodymium YAG with argon. Trans Ophthalmol Soc UK 1984;104:67-9.

${ }^{12}$ Moster MR, Schwartz LW, Spaeth GL, Wilson RP, McAllister JA, Poryzees EM: Laser iridectomy. A controlled study comparing argon and neodymium: YAG. Ophthalmology 1986;93:20-4.

${ }^{13}$ Playfair TJ and Watson PG: Management of acute primary angle-closure glaucoma: a long term follow-up of the results of peripheral iridectomy used as an initial procedure. $\mathrm{Br} \mathrm{J}$ Ophthalmol 1979,63:17-22.

${ }^{14}$ Mapstone R: Provocative tests in closed-angle glaucoma. Br J Ophthalmol 1976;60:115-9.

${ }^{15}$ Harrad RA, Stannard KP, Shilling, JS: Argon Laser iridotomy. Br J Ophthalmol 1985:69:368-72.

${ }^{16}$ Fleck BW: How large must an iridotomy be? $\mathrm{Br} \mathrm{J}$ Ophthalmol 1990;74:583-8.
${ }^{17}$ Lowe RF: Acute angle closure glaucoma. The second eye an analysis of 200 cases. Br JOphthalmol 1962;46:641-50.

${ }^{18}$ Lowe RF: Primary angle-closure glaucoma. A review 5 years after bilateral surgery. $\mathrm{Br} J \mathrm{Oph}$ thalmol 1973;57:457-63.

${ }^{19}$ Mandelkorn R, Mendelsohn A, Olander K, Zimmerman TJ: Short exposure times in argon laser iridotomy. Ophthalmic Surg 1981;12:805-9.

${ }^{20}$ Brainard JO, Landers JH, Shock JP: Recurrent angle closure glaucoma following a patent 75 micron laser iridotomy: a case report. Ophthalmic Surg 1982;13:1030-2.

${ }^{21}$ Wishart PK and Hitchings RA: Neodymium: YAG and dye laser iridotomy-a comparitive study. Trans Ohthalmol Soc UK 1986;105:521-40.

${ }^{22}$ Gray RH, Hoare Nairn J, Ayliffe WHR: Efficacy of $\mathrm{Nd}$ : YAG laser iridotomies in acute angle-closure glaucoma. Br J Ophthalmol 1989;73:182-5.

${ }^{23}$ Brazier DJ: Neodymium: YAG laser iridotomy. $J$ Roy Soc Med 1989;79:658-60.

${ }^{24}$ Naveh N, Zborowsky-Gutman L, Blumenthal M: Neodymium: YAG laser iridotomy in angle closure glaucoma: preliminary study. $\mathrm{Br} J \mathrm{Oph}$ thalmol 1987;71:257-61.

${ }^{25}$ Stilma JS, Boen Tan TN: Timolol and intra-ocular pressure elevation following neodymium: YAG laser surgery. Doc Ophthalmol 1986;61:233-9.

${ }^{26}$ Kitazawa Y, Taniguchi T, Sugiyama K: Use of apraclonadine to reduce acute intraocular pressure. rise following Q-Switched Nd:YAG laser iridotomy. Ophthalmic Surg 1989;20:49-52.

${ }^{27}$ Kerr-Muir MG and Sherrard ES: Damage to the corneal endothelium during Nd:YAG photodisruption. Br J Ophthalmol 1985;69:77-85.

${ }^{28}$ Canning CR, Capon MR, Sherrard ES, Kerr Muir MG, Pearson R, Cooling R: Neodymium:YAG laser iridotomies: short-term comparison with capsulotomies and long-term follow-up. Graefes Arch Clin Exp Ophthalmol 1988;226:49-54.

${ }^{29}$ Smith J and Whitted P: Corneal endothelial changes after argon laser iridotomy. Am J Ophthalmol 1984;98:153-6.

${ }^{30}$ Wishart PK, Sherrard ES, Nagasubramanian S, Kerr Muir MG, Hitchings RA: Corneal endothelial changes following short pulsed laser iridotomy and surgical iridectomy. Trans Ophthalmol Soc UK 1986;105:541-8.

${ }^{31}$ Markowitz SN and Morin JD: The endothelium in primary angle-closure glaucoma. Am J Ophthalmol 1984;98:103-4.

${ }^{32}$ Montgomery DMI and Dutton GN: Correspondence: Intralenticular haemorrhage complicating pulsed laser iridotomy. $\mathrm{Br} J$ Ophthalmol 1987;71:484.

${ }^{33}$ Krupin T, Mitchell MB, Johnson MF, Becker B: The long term effects of iridectomy for primary acute angle-closure glaucoma. Am J Ophthalmol 1978;86:506-9.

${ }^{34}$ Godel V, Regenbogen L: Cataractogenic factors in patients with primary angle-closure glaucoma after peripheral iridectomy. Am J Ophthalmol 1977;83:180-4. 